\title{
Efficacy of frovatriptan in the acute treatment of menstrually related migraine: analysis of a double-blind, randomized, cross-over, multicenter, Italian, comparative study versus rizatriptan
}

\author{
Lidia Savi • Stefano Omboni · Carlo Lisotto • \\ Giorgio Zanchin · Michel D. Ferrari • \\ Dario Zava $\cdot$ Lorenzo Pinessi
}

Received: 12 April 2011 / Accepted: 9 July 2011/Published online: 13 August 2011

(C) The Author(s) 2011. This article is published with open access at Springerlink.com

\begin{abstract}
The objectives of this study are to assess the efficacy and safety of frovatriptan, and rizatriptan in the subgroup of women with menstrually related migraine of a multicenter, randomized, double blind, cross-over study. Each patient received frovatriptan $2.5 \mathrm{mg}$ or rizatriptan $10 \mathrm{mg}$ in a randomized sequence: after treating 3 episodes of migraine in not more than 3 months with the first treatment, the patient had to switch to the other treatment. Menstrually related migraine was defined according to the criteria listed in the Appendix of the last IHS Classification of Headache disorders. 99 out of the 125 patients included in the intention-to-treat analysis of the main study were of a female gender: 93 had regular menstrual cycles and were, thus, included in this analysis. A total of 49 attacks classified as menstrually related migraine were treated with frovatriptan and 59 with rizatriptan. Rate of pain relief at
\end{abstract}

L. Savi · L. Pinessi (ه)

Neurologia II, Department of Neurology, Centro Cefalee, University of Torino, Via Cherasco 15, 10126 Turin, Italy

e-mail: lorenzo.pinessi@unito.it

S. Omboni

Italian Institute of Telemedicine, Varese, Italy

C. Lisotto

Ospedale Civile San Vito al Tagliamento,

San Vito al Tagliamento, Italy

G. Zanchin

Department of Neurology, University of Padova, Padova, Italy

\section{D. Ferrari}

Leiden Centre for Translational Neuroscience,

Department of Neurology, Leiden University Medical Centre,

Leiden, The Netherlands

D. Zava

Istituto Lusofarmaco d'Italia, Milan, Italy
$2 \mathrm{~h}$ was $58 \%$ for frovatriptan and $64 \%$ for rizatriptan $(p=\mathrm{NS})$, while rate of pain free at $2 \mathrm{~h}$ was 31 and $34 \%$ $(p=\mathrm{NS})$, respectively. At $24 \mathrm{~h}, 67$ and $81 \%$ of frovatriptan-treated, and 61 and $74 \%$ of rizatriptan-treated patients were pain free and had pain relief, respectively $(p=\mathrm{NS})$. Recurrence at $24 \mathrm{~h}$ was significantly $(p<0.01)$ lower with frovatriptan (10 vs. $32 \%$ rizatriptan). Frovatriptan was as effective as rizatriptan in the immediate treatment of menstrually related migraine attacks while showing a favorable sustained effect with a lower rate of migraine recurrence. These results need to be confirmed by randomized, double-blind, prospective, large clinical trials.

Keywords Migraine - Menstrually related migraine · Frovatriptan · Rizatriptan

\section{Introduction}

The high prevalence of migraine in the female population is well established: approximately one-quarter of women experience migraine at some time in their lives and over half of them report an association between menstruation and migraine [1]. Menstrually related migraine leads to substantial disability and attacks are more severe, longer in duration, and have a poorer response to analgesics than episodes occurring in other time of the month [2]. Drug prophylaxis may be useful for menstrual migraine [3].

Triptans have proved to be the most effective acute treatment of migraine headaches and are preferable for menstrual migraine in view of its difficult-to-treat nature $[4,5]$. Prospective, randomized, controlled trials as well as retrospective analyses and open label studies support the use of triptans as acute therapy for menstrual migraine [5]. Sumatriptan, the first triptan to be marketed, has been 
shown to be well tolerated and effective in providing pain relief in menstrually associated migraine when administered in the mild pain phase, also in combination with analgesics [6-12]. Second generation triptans such as zolmitriptan [13-15], naratriptan [16], rizatriptan [17-21] and more recently almotriptan $[14,22]$ and frovatriptan [23] have been also successfully tested: the different pharmacokinetic and pharmacodynamic features of these triptans as respect to sumatriptan potentially render them particularly suitable for treating menstrual migraine. Following extensive evidence from prospective, double-blind, randomized, controlled studies, recent guidelines now recommend sumatriptan 50 and $100 \mathrm{mg}$ or rizatriptan $10 \mathrm{mg}$ for acute treatment of menstrually related migraine, and frovatriptan $2.5 \mathrm{mg}$ or naratriptan $1 \mathrm{mg}$ twice daily for preventive treatment of this condition [4, 24].

The preventive efficacy of frovatriptan has been largely demonstrated by randomized, double-blind, placebo controlled or open label studies [25-29]. Frovatriptan has been proved to be effective also in the acute management of menstrual migraine [30], including oral-contraceptiveinduced menstrual migraine a subtype of menstrual migraine caused by estrogen withdrawal occurring during the week of pill suspension [31]. More recently, in an openlabel post-marketing surveillance study conducted in women with migraine associated with menses, acute frovatriptan treatment improved patients' ratings of treatment effectiveness and tolerability as compared to previously used triptans [32].

Since there are presently no studies comparing the efficacy of frovatriptan with that of another second generation triptan in menstrual migraineurs, an analysis of a recently published double-blind, randomized, cross-over study, comparing the efficacy of frovatriptan versus rizatriptan [33] has been carried out in a subgroup of women with menstrually related migraine and is reported in the present paper.

\section{Methods}

\section{Study population}

Subjects of both genders, aged 18-65 years, with a current history of migraine with or without aura, according to International Headache Society (IHS) 2004 criteria, and with at least one, but not more than 6 migraine attacks per month for 6 months prior to entering the study, were enrolled in the main study $[33,34]$. In the present analysis, women with menstrually related migraine were selected. This condition was defined according to IHS criteria as migraine without aura attacks in a menstruating woman, occurring on day $1 \pm 2$ (namely days -2 to +3 ) of menstruation in at least 2 out of 3 menstrual cycles and additionally at other times of the cycle [34].

Main exclusion criteria were: (a) uncontrolled hypertension; (b) ischemic heart disease; (c) cardiac arrhythmias or symptomatic Wolff-Parkinson-White syndrome; (d) previous stroke or transient ischemic attack; (e) severe liver or renal impairment; (f) any other severe or disabling medical condition; ( $\mathrm{g}$ ) history of alcohol or analgesic or psychotropic drug abuse; (h) known hypersensitivity to study drugs; (i) previously demonstrated inadequate response to at least two triptans; (j) current use of propranolol or ergothamine (and its derivatives) as a prophylactic agent; (k) current use or use in the previous 2 weeks of MAO-inhibitors; (l) use of either test medication to treat any one of the last three episodes of migraine; and (m) other headaches that have been lasting for more than 6 days. Pregnant women and breast-feeding mothers were excluded as well, while women with childbearing potential but not practicing an effective method of birth control were to be submitted to a pregnancy test, if clinically indicated.

All patients gave written informed consent prior to their inclusion into the study. The study was approved by the Independent Institutional Review Boards of the study centers.

\section{Study design}

Details on the study design are available in a previous publication [33]. Briefly, this was a multicenter, randomized, double blind, cross-over study, including 14 Italian centers (see Appendix). Each patient received frovatriptan $2.5 \mathrm{mg}$ or rizatriptan $10 \mathrm{mg}$ in a randomized sequence: after treating 3 episodes of migraine in not more than 3 months with the first treatment, the patient had to switch to the other treatment. Subjects were encouraged to treat 1 to 3 attacks for a maximum period of 6 months and to visit the center three times. Subjects having no migraine episodes during one of the two observation periods were excluded from the study.

During the randomization visit, after signing written informed consent, subjects provided a medical, treatment and migraine history. A physical and neurological examination and pregnancy test (if appropriate) were performed. Blood pressure and heart rate were measured for all the subjects. The degree of migraine-associated disability (MIDAS questionnaire) was also completed. At the end of the visit, a headache diary documenting characteristics of headache pain (including its relation with menses) and associated symptoms was dispensed with study medication. Subjects were instructed to treat at least 3 migraine episodes occurring in not more than 3 months and to come for the second visit. On this occasion, use of concomitant medications and occurrence of adverse events (from diary) 
were checked, blood pressure and heart rate were recorded, and a pregnancy test performed, if deemed necessary. The same procedures were carried out at the end of the second study treatment period or at the early withdrawal visit.

Patients were instructed to take one dose of study medication as early as possible after the onset of migraine attack. If insufficient relief had been obtained after $2 \mathrm{~h}$, patients were allowed to take a second dose of study medication, with a maximum daily intake of two doses. In case of insufficient relief $1 \mathrm{~h}$ after the intake of the second dose of the study medication, patients were allowed to take a rescue medication. Alternate rescue medication could not include triptans, or contain ergotamine or its derivatives, or propranolol.

Data analysis

This analysis was carried out in all normally menstruating women randomized to any of the two treatment sequences, having not positively refused to receive either study treatment and having treated at least one episode of menstrual migraine with both medications (intention-to-treat population).

The study endpoints were defined [34], as (a) the number of pain relief episodes at $2 \mathrm{~h}$ (a decrease in migraine intensity from severe or moderate to mild or none at $2 \mathrm{~h}$ ); (b) the number of pain free episodes at $2 \mathrm{~h}$ (absence of migraine episodes at $2 \mathrm{~h}$ after intake of one dose of study drug); (c) the number of pain free episodes at $24 \mathrm{~h}$ (absence of migraine episodes at $24 \mathrm{~h}$ ); (d) the number of pain relief episodes at $24 \mathrm{~h}$ (a decrease in migraine intensity from severe or moderate to mild or none at $24 \mathrm{~h}$ ); and (e) recurrence within $24 \mathrm{~h}$ (episodes pain free at $2 \mathrm{~h}$ and headache of any severity returns within $24 \mathrm{~h}$ or intake of a second study drug or rescue medication). Consistency of response (responders in 2 and 3 out of 3 attacks) was also assessed for each study endpoint.

Changes in headache intensity from baseline after 2, 4, 24 and $48 \mathrm{~h}$ from study drug intake, were also evaluated. Analysis of pain free episodes was carried out also according to baseline headache intensity (mild, moderate or severe). Frequency of pain free and pain relief episodes was also assessed and compared between menstrually and non-menstrually related migraine attacks.

Continuous variables were summarized by computing average values and standard deviation (SD), while categorical variables by computing the absolute value and the frequency (as percentage). Endpoints were compared between groups by generalized estimating equation analysis. Kaplan-Meyer curves for cumulative hazard of recurrence over the $48 \mathrm{~h}$ were also drawn. $p$ value refers to the statistical significance of between treatment difference. The level of statistical significance was kept at 0.05 throughout the whole study.

\section{Results}

Overall 125 subjects formed the main study population [29]: 99 of them were of a female gender and 93 had a regular menstrual cycle and were, thus, included in this analysis.

Main demographic and clinical characteristics of the patients of the whole study population and of the subgroup of women with menstrually related migraine are reported in Table 1. As compared to the main study population, the women of this analysis were less tall $(p<0.01$ between groups) and thinner $(p<0.01)$, and had a higher MIDAS score $(p<0.05)$. The proportion of patients suffering from attacks lasting more than 2 days was larger in the group of women with menstrual migraine ( 25 women vs. 1 woman with non-menstrual migraine, $p<0.05$ ).

Overall efficacy of study drugs

49 attacks (17\% of all attacks) classified as menstrually related migraine were treated with frovatriptan and 59 $(21 \%)$ with rizatriptan.

The proportion of pain relief episodes was similar $(p=\mathrm{NS})$ between frovatriptan and rizatriptan at $2 \mathrm{~h}(58$ vs. $64 \%)$ and at $24 \mathrm{~h}$ ( 81 vs. $74 \%)$. Also, the rate of pain free episodes at 2 and $24 \mathrm{~h}$ did not differ between the two
Table 1 Demographic and clinical baseline data of the 125 patients of the main study (33) and of the subgroup of 93 women with menstrually related migraine

Data are shown as mean $( \pm \mathrm{SD})$, or absolute $(n)$ and relative frequency $(\%)$

\begin{tabular}{llll}
\hline & $\begin{array}{l}\text { Main study } \\
n=125\end{array}$ & $\begin{array}{l}\text { Menstruating Women } \\
n=93\end{array}$ & $p$ \\
\hline Age (years, means $\pm \mathrm{SD})$ & $37 \pm 9$ & $36 \pm 9$ & $\mathrm{NS}$ \\
Height $(\mathrm{cm}$, means $\pm \mathrm{SD})$ & $167 \pm 9$ & $163 \pm 7$ & $<0.01$ \\
Weight $(\mathrm{kg}$, means $\pm \mathrm{SD})$ & $64 \pm 13$ & $59 \pm 8$ & $<0.01$ \\
Age at onset of migraine (years, means $\pm \mathrm{SD})$ & $16 \pm 7$ & $16 \pm 6$ & $\mathrm{NS}$ \\
Migraine attack duration $>2$ days $(n, \%)$ & $26(21)$ & $25(28)$ & $\mathrm{NS}$ \\
MIDAS score (means $\pm \mathrm{SD})$ & $22 \pm 15$ & $26 \pm 17$ & $<0.05$ \\
\hline
\end{tabular}


Table 2 Main study endpoints in the two study treatment groups

\begin{tabular}{llll}
\hline & Frovatriptan & Rizatriptan & $p$ \\
\hline Pain relief episodes at 2 h & $25(58)$ & $27(64)$ & NS \\
Pain free episodes at 2 h & $15(31)$ & $20(34)$ & NS \\
Pain relief episodes at 24 h & $35(81)$ & $31(74)$ & NS \\
Pain free episodes at 24 h & $33(67)$ & $36(61)$ & NS \\
Recurrent episodes at 24 h & $5(10)$ & $19(32)$ & $<0.01$
\end{tabular}

Data are reported as absolute $(n)$ and relative $(\%)$ frequency. P refers to the statistical significance of the difference between the two study drugs

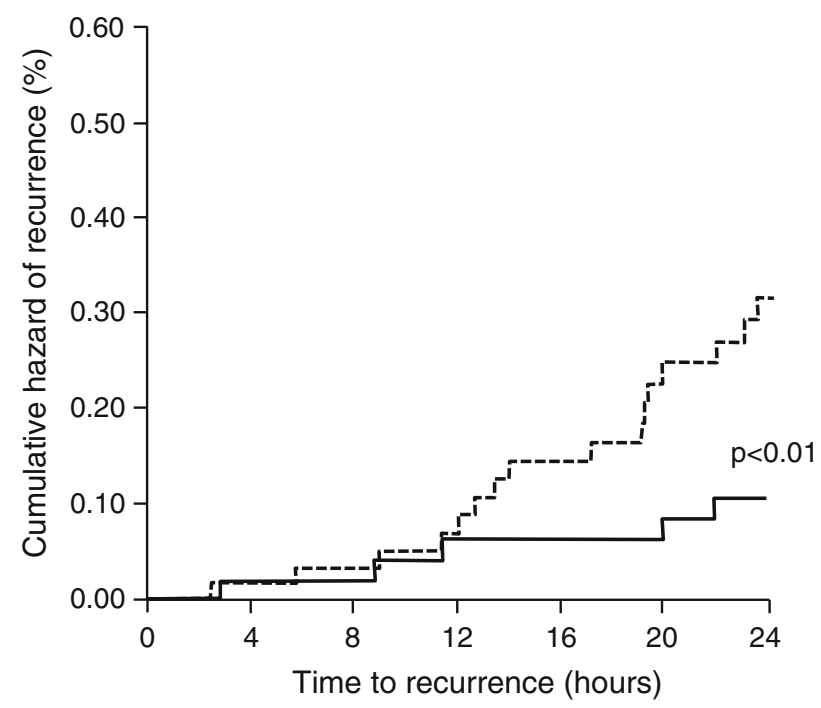

Fig. 1 Cumulative hazard of recurrence over the $24 \mathrm{~h}$ during treatment with frovatriptan (continuous line) or rizatriptan (dashed line) in the 93 women with menstrually related migraine included in this analysis

treatment groups (31 and 67\% frovatriptan vs. 34 and $61 \%$ rizatriptan; $p=$ NS for both) (Table 2).

The rate of migraine recurrence after $24 \mathrm{~h}$ was significantly $(p<0.01)$ lower under frovatriptan $(10 \%)$ than under rizatriptan (32\%). Also, the cumulative hazard of recurrence during the follow-up was significantly $(p<0.01)$ lower under frovatriptan (Fig. 1).

Consistency of response never resulted significantly different between the two groups, even for recurrences, probably due to the low number of subjects available for this sub-analysis (Table 3).

Efficacy of study drugs according to baseline migraine intensity

Most of the treated attacks had a moderate or severe intensity at baseline. When rate of pain free episodes at 2 and $24 \mathrm{~h}$ was compared between treatments according to baseline migraine severity, frovatriptan was superior to
Table 3 Results of consistency analysis in the two study treatment groups

\begin{tabular}{llll}
\hline & Frovatriptan & Rizatriptan & $p$ \\
\hline Pain relief episodes at 2 h & $19(76)$ & $20(74)$ & NS \\
Pain free episodes at 2 h & $11(73)$ & $16(80)$ & NS \\
Pain relief episodes at 24 h & $28(80)$ & $25(81)$ & NS \\
Pain free episodes at 24 h & $23(70)$ & $23(64)$ & NS \\
Recurrent episodes at 24 h & $3(60)$ & $16(84)$ & NS \\
\hline
\end{tabular}

Consistency of was response was defined as responders in 2 and 3 out of 3 attacks. Data are reported as absolute $(n)$ and relative (\%) frequency. $p$ refers to the statistical significance of the difference between the two study drugs

Table 4 Absolute $(n)$ and relative (\%) frequency of pain free episodes at 2 and $24 \mathrm{~h}$ according to baseline headache intensity in the two treatment groups

\begin{tabular}{lllll}
\hline & Frovatriptan & Rizatriptan & $p$ \\
\hline $\begin{array}{l}\text { Pain free episodes at } \\
2 \text { hours } \\
\text { Mild }\end{array}$ & $3(20)$ & $8(40)$ & - & NS \\
$\begin{array}{l}\text { Moderate-severe } \\
\begin{array}{l}\text { Pain free episodes at } \\
24 \text { hours } \\
\text { Mild }\end{array}\end{array}$ & $12(80)$ & $12(60)$ & & \\
Moderate-severe & $31(94)$ & $23(76)$ & & $<0.01$ \\
\hline
\end{tabular}

$p$ refers to the statistical significance of the difference between the two study drugs

rizatriptan at $2 \mathrm{~h}$ and at $24 \mathrm{~h}$ for treatment of moderate to severe attacks, with a statistically significant between treatment difference at $24 \mathrm{~h}(p<0.01$, Table 4$)$.

Changes in migraine intensity

During the $48 \mathrm{~h}$ observation period, migraine intensity was progressively reduced by both drugs, but in a significantly larger degree with frovatriptan, particularly between 24 and 48 h (Fig. 2).

Menstrually and non-menstrually related migraine attacks

Table 5 shows the number and proportion of pain free and pain relief-episodes at 2 and $24 \mathrm{~h}$ after frovatriptan intake for the 49 attacks related to and for the 233 attacks unrelated to the menstrual cycle. Frequency of pain relief at 2 and $24 \mathrm{~h}$ was 58 and $81 \%$ in menstrually related attacks and 54 and $87 \%$ in non-menstrually related attacks, with no statistically significant difference between the two types of 


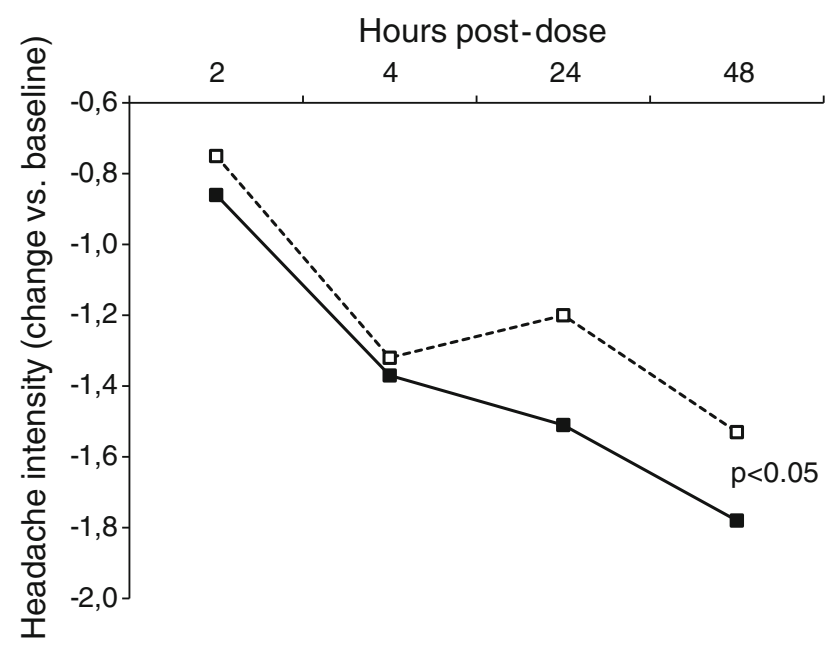

Fig. 2 Changes in migraine intensity from baseline during treatment with frovatriptan (continuous line) or rizatriptan (dashed line) in the 93 women with menstrually related migraine included in this analysis

Table 5 Absolute $(n)$ and relative (\%) frequency of pain free and pain relief episodes at 2 and $24 \mathrm{~h}$ in menstrually $(n=49)$ and nonmenstrually related $(n=233)$ migraine attacks treated with frovatriptan. $p$ refers to the statistical significance of the difference between the two types of migraine attacks

\begin{tabular}{llll}
\hline & $\begin{array}{l}\text { Menstrually } \\
\text { related } \\
\text { migraine }\end{array}$ & $\begin{array}{l}\text { Non-menstrually } \\
\text { related migraine }\end{array}$ & $p$ \\
\hline Pain relief episodes at 2 $\mathrm{h}$ & $25(58)$ & $100(54)$ & $\mathrm{NS}$ \\
Pain free episodes at 2 $\mathrm{h}$ & $15(31)$ & $77(33)$ & $\mathrm{NS}$ \\
Pain relief episodes at 24 h & $35(81)$ & $159(87)$ & NS \\
Pain free episodes at 24 h & $33(67)$ & $184(80)$ & NS \\
\hline
\end{tabular}

migraine $(p=\mathrm{NS})$. Similarly, the rate of pain free episodes at 2 and $24 \mathrm{~h}$ was 31 and $67 \%$ in menstrual migraine and 33 and $80 \%$ in non-menstrual migraine $(p=\mathrm{NS})$.

\section{Discussion}

In the present subgroup analysis of a double-blind, randomized, cross-over study, acute treatment of menstrually related migraine with frovatriptan and rizatriptan was associated with a similar immediate effect, as showed by similar proportions of pain relief and of pain free episodes at 2 and $24 \mathrm{~h}$ between the two drugs. However, frovatriptan showed significantly lower rates of headache recurrence over the $24 \mathrm{~h}$ than rizatriptan, this indicating a better sustained effect which can be explained by differences in pharmacological features of the two triptans. As a matter of fact, rizatriptan has a slightly shorter time to maximum concentration than frovatriptan, but the latter has a longer half-life (25-26 h vs. $2-3 \mathrm{~h}$ of rizatriptan), which might explain why frovatriptan, unlike rizatriptan, greatly reduced the risk of migraine recurrence [35-37].

The study provides also two important additional results, which are worthy being discussed. First, differences in drug efficacy were observed as a function of baseline migraine attack severity. In the women with migraine attacks of a moderate-severe intensity at baseline, the rate of pain free episodes at $24 \mathrm{~h}$ was significantly larger under frovatriptan. This is particularly relevant, considering that the subgroup of women with menstrually related migraine had a more disabling form of migraine as compared to the main study group, as confirmed by a significantly high MIDAS score and a larger proportion of patients with attacks of longer duration. Second, reduction in migraine intensity during the observation period was larger under frovatriptan, from 24 to $48 \mathrm{~h}$ after the onset of migraine attack and starting treatment, this confirming the more sustained pain relief effect of frovatriptan than rizatriptan.

This is the first study directly comparing the efficacy of frovatriptan as acute treatment of menstrually related migraine versus another triptan. Our study and a comparison study between almotriptan and rizatriptan [14], are the only two available head-to-head double-blind, randomized studies comparing the efficacy of two triptans in menstrual migraine. Though both studies share the limitations of subgroup analyses, they are useful because no such prospective studies on triptans in menstrual migraine have yet been carried out. Results of our study adds to the evidence of previous randomized, placebo controlled or open label studies proving the efficacy of frovatriptan as intermittent preventive [25-29] or acute treatment of menstrual migraine [30-32]. In published reports, prophylactic treatment with frovatriptan, started 2 days before the expected onset of headache and continued for 6 days, was always superior to placebo in reducing the frequency of menstrual migraine. A randomized, double-blind, placebo controlled study involving 410 women showed a headache incidence of only $8 \%$ when frovatriptan was given at dosage of $2.5 \mathrm{mg}$ twice-daily and of $31 \%$ when given oncedaily, while the incidence was $58 \%$ under placebo [26]. A post-hoc analysis of a randomized, double-blind, placebo controlled study in a population of 179 women experiencing menstrual migraine showed a significantly less prevalence of menstrual migraine with frovatriptan $2.5 \mathrm{mg}$ twice $(38 \%)$ or once-daily $(51 \%)$ than with placebo $(67 \%)$ [27]. These latter results are in line with those of a previous randomized, double-blind, placebo-controlled study of the same authors carried out in 546 women migraineurs [28]. Concerning treatment of the acute attack, in a 6-month open label study frovatriptan was given at $2.5 \mathrm{mg}$ dose to 151 menstrual subjects for 2,439 migraine attacks, 659 of which occurring during a menstrual period [30]. Migraine relief within the $24 \mathrm{~h}$ was achieved for $82 \%$ of menstrual 
attacks, a proportion which was similar to that observed for non-menstrual attacks (87\%). In an open-label uncontrolled study, including 20 women with a history of oral contraceptive-induced menstrual migraine, pain relief was reported in $55 \%$ of women $2 \mathrm{~h}$ after drug intake $(58 \%$ in our study), while $10 \%$ of subjects were pain free after $2 \mathrm{~h}$ (31\% in our study), 35\% after $4 \mathrm{~h}$ and $60 \%$ after $24 \mathrm{~h}(67 \%$ in our study) [31]. Migraine intensity significantly decreased after $24 \mathrm{~h}$ by 1.6 , an extent similar to that observed in our study at the same time point (1.5).

Evidence as acute treatment of menstrual migraine is available also for rizatriptan. In the published studies, rate of pain relief episodes at $2 \mathrm{~h}$ with rizatriptan was $64-78 \%$ (18-21), rate of pain free episodes at $2 \mathrm{~h}$ was $50 \%$ [20], while pain relief at $24 \mathrm{~h}$ was $63 \%$ [17] and pain free at $24 \mathrm{~h}$ was 32-34\% [17, 20]: in our study, the corresponding figures for rizatriptan were very similar with respect to pain relief at $2 \mathrm{~h}(64 \%)$, slightly lower for pain free at $2 \mathrm{~h}(34 \%)$ and slightly higher for pain relief and pain free at $24 \mathrm{~h}(74$ and $61 \%$, respectively). No data on frequency of recurrences are available from previous studies on rizatriptan. Differences between our results and those of previous studies might be attributed to differences in study design and patients' characteristics: in particular, in some heterogeneity in the definition of menstrual migraine is evident among studies.

\section{Conclusions}

The present analysis of data from a multicenter, randomized, double-blind, head-to-head study suggests that frovatriptan and rizatriptan are similarly effective in the immediate treatment of women with menstrually related migraine. The study provides the first evidence that frovatriptan is superior to rizatriptan in reducing recurrence in menstrual migraine patients. The good sustained effect of frovatriptan shown in our study, seems to support indication of frovatriptan not only, as previously suggested, for preventive treatment of menstrual migraine [25-29], but also for managing the acute attack. The sustained analgesic effect of frovatriptan, supported by the lesser risk of recurrence may suggest the use of this drug for those patients with long-duration or recurrent migraine attacks [38, 39]. Caution must be taken when the drug is used within the same month for treating migraine attacks occurring during menses and outside the menstrual period, because of the risk of medication-overuse-headache, a risk which is, however, common to all triptans used for menstrual-migraine prophylaxis or treatment.

Given the retrospective design of our study, its results need to be confirmed by subsequent double-blind, randomized, prospective, large clinical trials.
Acknowledgements The present study was supported by Istituto Lusofarmaco d'Italia.

Conflict of interest All authors have occasionally served as scientific consultants for manufacturers of frovatriptan or rizatriptan. Dario Zava is an employee of the manufacturer of frovatriptan.

Open Access This article is distributed under the terms of the Creative Commons Attribution License which permits any use, distribution and reproduction in any medium, provided the original author(s) and source are credited.

\section{Appendix-list of study sites}

Coordinator L. Pinessi (Torino).

Investigators P. De Martino (Torino), B. Panascia (Palermo), R. Rapisarda (Palermo), F. Devetag (Feltre), M.G. Sances (Pavia), L.A. Pini (Modena), G. Bono (Varese), R. Cerbo (Roma), M. De Marinis (Roma), M. Guidotti, R. Ravasio (Como), M. Alessandri (Grosseto), E. De Caro (Catanzaro), F. Lanaia (Catania), M.P. Prudenzano (Bari),G. Reggiardo (Biostatistical Unit, Mediservice, Milano), F. Sacchi (Clinical Unit, Mediservice, Milano).

\section{References}

1. Martin VT, Lipton RB (2008) Epidemiology and biology of menstrual migraine. Headache 48(Suppl 3):S124-S130

2. Allais G, Castagnoli Gabellari I, De Lorenzo C, Mana O, Benedetto C (2007) Menstrual migraine: clinical and therapeutical aspects. Expert Rev Neurother 7:1105-1120

3. Recober A, Geweke LO (2005) Menstrual migraine. Curr Neurol Neurosci Rep 5:93-98

4. MacGregor EA (2010) Prevention and treatment of menstrual migraine. Drugs 70:1799-1818

5. Mannix LK, Files JA (2005) The use of triptans in the management of mestrua migraine. CNS Drugs 19:951-972

6. Facchinetti F, Allais G, Nappi RE, Gabellari IC, Di Renzo GC, Genazzani AR, Bellafronte M, Roncolato M, Benedetto C (2010) Sumatriptan (50 mg tablets vs. $25 \mathrm{mg}$ suppositories) in the acute treatment of menstrually related migraine and oral contraceptiveinduced menstrual migraine: a pilot study. Gynecol Endocrinol 26:773-779

7. Mannix LK, Martin VT, Cady RK, Diamond ML, Lener SE, White JD, Derosier FJ, McDonald SA (2009) Combination treatment for menstrual migraine and dysmenorrhea using sumatriptan-naproxen: two randomized controlled trials. Obstet Gynecol 114:106-113

8. Schreiber CP, Cady RK (2007) Diagnosis of menstrual headache and an open-label study among those with previously undiagnosed menstrually related migraine to evaluate the efficacy of sumatriptan $100 \mathrm{mg}$. Clin Ther 29(Suppl):2511-2519

9. Dowson AJ, Massiou H, Aurora SK (2005) Managing migraine headaches experienced by patients who self-report with menstrually related migraine: a prospective, placebo-controlled study with oral sumatriptan. J Headache Pain 6:81-87

10. Landy S, Savani N, Shackelford S, Loftus J, Jones M (2004) Efficacy and tolerability of sumatriptan tablets administered 
during the mild-pain phase of menstrually associated migraine. Int J Clin Pract 58:913-919

11. Nett R, Landy S, Shackelford S, Richardson MS, Ames M, Lener M (2003) Pain-free efficacy after treatment with sumatriptan in the mild pain phase of menstrually associated migraine. Obstet Gynecol 102:835-842

12. Salonen R, Saiers J (1999) Sumatriptan is effective in the treatment of mestrua migraine: a review of prospective studies and retrospective analyses. Cephalalgia 19:16-19

13. Tuchman M, Hee A, Emeribe U, Silberstein S (2006) Efficacy and tolerability of zolmitriptan oral tablet in the acute treatment of menstrual migraine. CNS Drugs 20:1019-1026

14. Allais G, Acuto G, Cabarrocas X, Esbri R, Benedetto C, Bussone G (2006) Efficacy and tolerability of almotriptan versus zolmitriptan for the acute treatment of menstrual migraine. Neurol Sci 27(Suppl 2):S193-S197

15. Loder E, Silberstein SD, Abu-Shakra S, Mueller L, Smith T (2004) Efficacy and tolerability of oral zolmitriptan in menstrually associated migraine: a randomized, prospective, parallel-group, double-blind, placebo-controlled study. Headache 44:120-130

16. Massiou H, Jamin C, Hinzelin G, Bidaut-Mazel C, French Naramig Collaborative Study Group (2005) Efficacy of oral naratriptan in the treatment of menstrually related migraine. Eur $\mathbf{J}$ Neurol 12:774-781

17. Bigal M, Sheftell F, Tepper S, Tepper D, Ho TW, Rapoport A (2008) A randomized double-blind study comparing rizatriptan, dexamethasone, and the combination of both in the acute treatment of menstrually related migraine. Headache 48:1286-1293

18. Nett R, Mannix LK, Mueller L, Rodgers A, Hustad CM, Skobieranda F, Ramsey KE (2008) Rizatriptan efficacy in ICHD-II pure menstrual migraine and menstrually related migraine. Headache 48:1194-1201

19. Martin V, Cady R, Mauskop A, Seidman LS, Rodgers A, Hustad CM, Ramsey KE, Skobieranda F (2008) Efficacy of rizatriptan for menstrual migraine in an early intervention model: a prospective subgroup analysis of the rizatriptan TAME (Treat A Migraine Early) studies. Headache 48:226-235

20. Silberstein SD, Massiou H, McCarroll KA, Lines CR (2002) Further evaluation of rizatriptan in menstrual migraine: retrospective analysis of long-term data. Headache 42:917-923

21. Silberstein SD, Massiou H, Le Jeunne C, Johnson-Pratt L, McCarroll KA, Lines CR (2000) Rizatriptan in the treatment of menstrual migraine. Obstet Gynecol 96:237-242

22. Diamond ML, Cady RK, Mao L, Biondi DM, Finlayson G, Greenberg SJ, Wright P (2008) Characteristics of migraine attacks and responses to almotriptan treatment: a comparison of menstrually related and nonmenstrually related migraines. Headache 48:248-258

23. Newman LC, Harper S, Jones BA, Campbell J (2009) Frovatriptan for acute treatment of migraine associated with menstruation: results from an open-label postmarketing surveillance study. J Womens Health (Larchmt) 18:1265-1273
24. Pringsheim T, Davenport WJ, Dodick D (2008) Acute treatment and prevention of menstrually related migraine headache: evidence-based review. Neurology 70:1555-1563

25. MacGregor EA, Pawsey SP, Campbell JC, Hu X (2010) Safety and tolerability of frovatriptan in the acute treatment of migraine and prevention of menstrual migraine: results of a new analysis of data from five previously published studies. Gend Med 7:88-108

26. Brandes JL, Poole A, Kallela M, Schreiber CP, MacGregor EA, Silberstein SD, Tobin J, Shaw R (2009) Short-term frovatriptan for the prevention of difficult-to-treat menstrual migraine attacks. Cephalalgia 29:1133-1148

27. Silberstein SD, Berner T, Tobin J, Xiang Q, Campbell JC (2009) Scheduled short-term prevention with frovatriptan for migraine occurring exclusively in association with menstruation. Headache 49:1283-1297

28. Silberstein SD, Elkind AH, Schreiber C, Keywood C (2004) A randomized trial of frovatriptan for the intermittent prevention of menstrual migraine. Neurology 63:261-269

29. Guidotti M, Mauri M, Barrilà C, Guidotti F, Belloni C (2007) Frovatriptan vs. transdermal oestrogens or naproxen sodium for the prophylaxis of mestrual migraine. J Headache Pain 8:283-288

30. Balbisi EA (2006) Frovatriptan: a review of pharmacology, pharmacokinetics and clinical potential in the treatment of menstrual migraine. Ther Clin Risk Manag 2:303-308

31. Allais G, Bussone G, Airola G, Borgogno P, Gabellari IC, De Lorenzo C, Pavia E, Benedetto C (2008) Oral contraceptiveinduced menstrual migraine. Clinical aspects and response to frovatriptan. Neurol Sci 29(Suppl 1):S186-S190

32. Newman LC, Harper S, Jones BA, Campbell J (2009) Frovatriptan for acute treatment of migraine associated with menstruation: results from an open-label postmarketing surveillance study. J Womens Health (Larchmt) 18:1265-1273

33. Savi L, Omboni S, Lisotto C, Zanchin G, Ferrari MD, Zava D, Pinessi L (2011) A double-blind, randomized, multicenter, Italian study of frovatriptan versus rizatriptan for the acute treatment of migraine. J Headache Pain 12:219-226

34. Headache Classification Subcommittee of the International Headache Society (2004) The International Classification of Headache Disorders, 2nd edn. Cephalalgia 24(Suppl 1):9-160

35. Loder E (2010) Triptan therapy in migraine. N Engl J Med 363:63-70

36. Balbisi EA (2004) Frovatriptan succinate, a 5-HT1B/1D receptor agonist for migraine. Int J Clin Pract 58:695-705

37. Markus F, Mikko K (2007) Frovatriptan review. Expert Opin Pharmacother 8:3029-3033

38. Kelman L (2008) Review of frovatriptan in the treatment of migraine. Neuropsychiatr Dis Treat 4:49-54

39. Cady R, Elkind A, Goldstein J, Keywood C (2004) Randomized, placebo-controlled comparison of early use of frovatriptan in a migraine attack versus dosing after the headache has become moderate or severe. Curr Med Res Opin 20:1465-1472 